\title{
Management of radiation cystitis
}

Shaun G. Smit \& Chris F. Heyns

Department of Urology, University of Stellenbosch and Tygerberg Hospital, PO Box 19063, Tygerberg 7505, South Africa

\begin{abstract}
Acute radiation cystitis occurs during or soon after radiation treatment. It is usually self-limiting, and is generally managed conservatively. Late radiation cystitis, on the other hand, can develop from 6 months to 20 years after radiation therapy. The main presenting symptom is hematuria, which may vary from mild to severe, life-threatening hemorrhage. Initial management includes intravenous fluid replacement, blood transfusion if indicated and transurethral catheterization with bladder washout and irrigation. Oral or parenteral agents that can be used to control hematuria include conjugated estrogens, pentosan polysulfate or WF10. Cystoscopy with laser fulguration or electrocoagulation of bleeding points is sometimes effective. Injection of botulinum toxin A in the bladder wall may relieve irritative bladder symptoms. Intravesical instillation of aluminum, placental extract, prostaglandins or formalin can also be effective. More-aggressive treatment options include selective embolization or ligation of the internal iliac arteries. Surgical options include urinary diversion by percutaneous nephrostomy or intestinal conduit, with or without cystectomy. Hyperbaric oxygen therapy (HBOT) involves the administration of $100 \%$ oxygen at higher than atmospheric pressure. The reported success rate of HBOT for radiation cystitis varies from $60 \%$ to $92 \%$. An important multicenter, doubleblind, randomized, sham-controlled trial to evaluate the effectiveness of HBOT for refractory radiation cystitis is currently being conducted.
\end{abstract}

\section{Introduction}

Radiation can be defined as the emission of energy by one body, its transmission through an intervening medium and its absorption by another body. The term 'radiation' refers to an electromagnetic spectrum that comprises, amongst others, alpha, beta and gamma particles. Gamma particles (X-rays) emit high-energy radiation, and can be used for therapeutic benefit. ${ }^{1}$

Radiation therapy aims to deliver high doses of radiation to target organs whilst simultaneously respecting the normal tolerance of surrounding tissues - that is, to eradicate the tumor while preserving the structure and function of other organs. Advances in radiation therapy, such as highenergy linear accelerators, conformal radiation therapy (CRT) and intensity-modulated radiation therapy (IMRT), have allowed higher doses of radiation to be delivered to the tumor whilst sparing surrounding tissues. Despite these advances, tissue injury to non-target organs does still occur.

The aim of this Review is to accurately describe the pathophysiology, pathology, clinical presentation and management of late radiation cystitis.

\section{Pathophysiology}

The effects of radiation on a cellular level are twofold. A somatic effect is caused by radiolysis of water, resulting in the production of activated free oxygen radicals (hydroxyl and superoxide radicals). These highly reactive radicals cause lipid peroxidation, which induces cell membrane injury and immediate cell death. Genetic damage is caused directly by absorption of energy by DNA (according to target theory), as well as indirectly via reaction of DNA with oxygen radicals. This can lead to mutation and/or replication failure, and ultimately delayed cell death. ${ }^{\underline{1}}$

The radiosensitivity of different tissues varies, depending largely on their proliferative rate. Normal bladder epithelium has a low proliferative rate, and is thus sensitive to radiation. In general, intermediate and basal urothelial cells show signs of damage within 3 months of radiation exposure. 
By 6-12 months, a radiation-dose-dependent increase in proliferative activity of the urothelium is usually evident. Tight junctions and the normal proteoglycan layer may be lost as a result of urothelial radiation injury, which interrupts the barrier between urine and bladder tissue. This correlates with the onset of irritative lower urinary tract symptoms that are commonly encountered after radiation therapy. Vascular endothelial cell edema also occurs early after radiation exposure (within 3 months), with endothelial cell proliferation seen $>6$ months after radiation. Additional signs of endothelial cell damage and perivascular fibrosis occur by 6-12 months, potentially resulting in vascular occlusion and focal bladder ischemia. ${ }^{3}$

The smooth muscle of the urinary bladder is also sensitive to radiation. Edema occurs early and may be followed by cellular destruction. Normal smooth muscle may be replaced by fibroblasts, ultimately leading to increased collagen deposition. Such changes lead to decreased bladder compliance and functional changes in bladder capacity. Late bladder fibrosis is secondary to vascular ischemia. Thus, the target for late bladder damage seems to be vascular endothelial cells. Changes in endothelial cells are seen months to years following radiation therapy, and are not prominent at earlier time periods. Injury to the epithelial cell layer does not seem to have an important role in the development of late effects. . $^{-}$

\section{Pathology}

Acute radiation tissue injury to the bladder is caused primarily by damage to the bladder mucosa, which contains cells that divide rapidly. This usually occurs during the treatment period, and involves an acute inflammatory response and tissue edema. ${ }^{4}$

The underlying pathology of late adverse effects is different from that seen in the acute reaction. Late-responding tissues, such as vascular and connective tissues, have a slow turnover rate; therefore, while they sustain radiation damage at the time of treatment, the effects are not expressed until repeated cell division is attempted. ${ }^{4}$ For this reason, late radiation tissue injury can take several months to many years to develop, and is largely a function of the total radiation dose and fraction size. The pathological hallmark of late radiation tissue injury is obliterative endarteritis resulting in atrophy and fibrosis. Tissue damaged by radiation is often referred to as "three- $\mathrm{H}$ tissue" (hypovascular, hypocellular and hypoxic). The capability to replace normal collagen and cell loss is compromised in hypoxic conditions, which results in tissue breakdown. This causes the bladder mucosa to become necrotic and slough off, leading to hematuria. Impaired healing under ischemic conditions can lead to ulcer and fistula formation. Telangiectasia (permanent dilation of blood vessels, usually in the mucous membranes) develops, and can also cause bleeding. Fibrosis forms part of the repair process and, if severe, can lead to a reduction in bladder capacity. ${ }^{3}$

\section{Clinical presentation}

Acute radiation cystitis occurs either during or shortly after radiation treatment. Symptoms experienced include dysuria and increased urinary frequency and urgency. This condition is usually self-limiting, and seldom persists for longer than 3 months after radiation therapy. Standard management is, therefore, conservative: symptomatic relief with the use of anticholinergic drugs (such as oxybutynin chloride) is usually sufficient. Alternative treatment options include phenazopyridine hydrochloride and flavoxate hydrochloride. ${ }^{\underline{3}}$

Late radiation cystitis following radiation therapy for cancers in the pelvic region has an incidence of $5-10 \%$. Levenback et al. .5 reported an incidence of $6.5 \%$ in 1,784 patients with stage $1 \mathrm{~b}$ cervical cancer treated with radiation therapy over a period of 29 years. Radiation cystitis is most common in patients with bladder cancer treated with radiation: in a review of 10-year survivors of bladder cancer treated with definitive radiation therapy, $10 \%$ of patients developed contracted bladders.. Other studies report incidences in the range of $2-47 \% .{ }^{3}$ Late radiation cystitis can develop from at 
least 6 months to as long as 20 years after radiation treatment, with a mean latent period of 35 months.

Several patient, tumor and treatment factors might increase the risk of developing late radiation cystitis. Pre-existing medical conditions, such as diabetes, hypertension and previous unrelated abdominal surgery, are important factors. Tumor stage determines the volume of tissue irradiated and the overall dose of radiation administered. Surgery, postoperative complications and chemotherapy are also important considerations in evaluating the baseline risk, and may contribute to the development of late radiation cystitis. Most important are factors related to the radiation treatment, including the volume of tissue treated, total bladder dose and fractionation, mode of delivery (external beam and/or brachytherapy), concurrent treatments and the radiosensitivity of the affected bladder tissue. . $^{-}$

Hematuria is the main presenting symptom, and can vary from mild hematuria to life-threatening hemorrhage. Hematuria with clot formation can lead to urinary retention. Other lower urinary tract symptoms, including pain, increased urinary frequency and urgency, and incontinence, may also be present.

\section{Diagnosis}

The clinical features of late radiation cystitis are nonspecific, and can also be caused by bladder infection or malignancy. Thus, diagnosis is focused on the exclusion of other causes of hematuria. Dipstick urinalysis and urine culture are essential to exclude infection, and urine cytology is valuable to detect high-grade malignancy. Upper urinary tract evaluation in the form of ultrasonography or excretory urography is also recommended. Lower urinary tract evaluation in the form of cystoscopy is mandatory, and may reveal erythema, edema, telangiectasia, bleeding ulcers, fistulas or fibrosis with reduction in bladder capacity. At the time of cystoscopy, bladder biopsy may be performed if there is suspicion of tumor recurrence, with particular attention to the potential risk of perforation of the irradiated bladder wall.

\section{Grading}

The EORTC (European Organisation for Research and Treatment of Cancer) and RTOG (Radiation Therapy Oncology Group) have produced standardized scoring scales for uniform reporting of radiation toxicity in different target organs. These scales include four elements, representing subjective, objective, management and analytical (SOMA) evaluation of late effects to normal tissues (LENT). Each individual organ or tissue known to be within the target irradiation zone, and hence at risk of being damaged, has its own LENT-SOMA scale, which is based on the original RTOG criteria for radiation morbidity. ${ }^{\underline{?}}$

The LENT-SOMA scale is a comprehensive system and provides much information, but it is difficult to implement in routine practice outside of clinical studies. ${ }^{-}$Instead, the severity of hematuria can be graded using both the RTOG/EORTC ${ }^{9}$ (Table 1) and NCI CTCAE (National Cancer Institute Common Terminology Criteria for Adverse Events $)^{10}$ grading systems, which are probably of more practical use and are, therefore, more widely used in clinical practice.

\section{Management}

Initial management of late radiation cystitis includes resuscitation of the patient if necessary. If hemorrhagic shock is present, aggressive intravenous fluid replacement is required, and blood transfusion is indicated if the patient's hematocrit is low. A transurethral catheter should be inserted and intermittent or continuous bladder irrigation started, which is continued until the urine becomes 
clear. Most patients will respond to conservative management; however, refractory cases will require alternative treatment options (Box 1 ), which are outlined below.

\section{Intravesical instillation}

A number of agents have been administered intravesically for the purpose of alleviating symptoms associated with late radiation cystitis. Although the mechanisms of action of these agents vary, the principles essentially include sterilization, lavage and arrest of focal bleeding points.

\section{Aluminum}

Aluminum salts, such as alum, are classified pharmacologically as astringents, and act by precipitating proteins on the cell surface and in interstitial spaces. This mechanism arrests capillary bleeding in mild cases, but in heavy bleeding the precipitant tends to clot, leading to clot retention, distension and more bleeding. .11 Local adverse effects include suprapubic pain and vesical tenesmus, which can

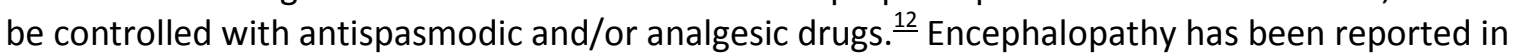
patients with renal failure, indicating that adequate renal function is essential for clearing a

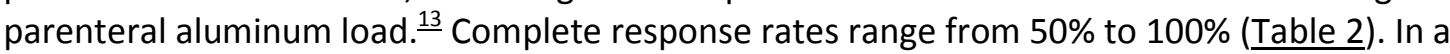
retrospective series of seven patients with radiation cystitis and hematuria treated with $1 \%$ aluminum sulfate as an intravesical lavage, Octavio Castillo and Buizza ${ }^{\underline{14}}$ reported good control of bleeding in all cases.

\section{Placental extract}

Placental extract is known to have a positive effect on the epithelialization of venous ulcers when applied topically, and, because of its wound-healing properties, has been used in the setting of radiation cystitis. Growth factors and angiogenic factors that have been isolated from the early placenta are thought to contribute to its healing effect on the mucosa. Micic and Genbacev ${ }^{15}$ performed a prospective observational study of 21 patients with chronic radiation cystitis treated with early placental extract, who all had relief of their urinary symptoms at 15 months. Objective improvement in bladder mucosal appearance on cystoscopy was reported in 18 of 21 patients. No adverse effects were noted.

\section{Prostaglandins}

Three case studies have been reported in which patients were successfully treated with intravesical prostaglandins: $; \frac{16,17,18}{1}$ however, whether the treatment results in these isolated reports were durable is not known. The protective mechanism of prostaglandins is probably mediated by increased cyclic AMP levels and stimulation of active sodium transport, with subsequent reductions in edema and the inflammatory response. ${ }^{4}$

\section{Formalin}

Formalin has been used in patients with severe radiation cystitis refractory to other treatment options. $.19,20,21,22,23,24$ Intravesical formalin instillation is performed under general or regional anesthesia once vesicoureteral reflux has been excluded. It causes precipitation of cellular proteins in the mucosa, producing an occlusive and fixative action on telangiectatic tissue and small capillaries. However, fixation of the bladder musculature may result in a small, contracted bladder, and fixation of the intramural ureter can also lead to obstruction with subsequent hydronephrosis and renal failure. Formalin is toxic even in very dilute (1\%) solution, and a recognized adverse effect is reflux leading to bilateral pyonephrosis with fatal sepsis..$^{21}$ Thus, it is recommended that intravesical formalin only be used when the bladder has been defunctioned by means of urinary diversion. 
Dewan et al. $\underline{21}$ reported on a retrospective series of 35 women with hemorrhagic radiation cystitis following radiation therapy for cervical cancer who were treated with $1 \%(n=22), 2 \%(n=10)$ or $4 \%$ $(n=4)$ intravesical formalin. After a single instillation, 31 patients $(89 \%)$ achieved complete responses and $3(8 \%)$ achieved partial responses. Minor complications were seen in 19 patients (54\%), and major complications occurred in 11 patients (31\%), 5 of whom required subsequent urinary diversion. One patient died of persistent bleeding and probable formalin toxicity. A $1 \%$ solution was as effective in controlling hematuria as higher concentrations, and was associated with significantly less morbidity.

Donahue and Frank ${ }^{24}$ published a meta-analysis on the use of formalin as an intravesical agent in 235 patients with intractable hemorrhagic cystitis. The overall complete response rates for $10 \%, 5 \%$ and $1 \%$ formalin were $83 \%, 78 \%$ and $71 \%$, respectively. Most patients responded within $48 \mathrm{~h}$, and the response was durable for a mean of 3-4 months. Interestingly, of those whose disease recurred, only $55 \%$ had a complete response to subsequent intravesical formalin instillation. $5 \%$ and $10 \%$ formalin solutions were associated with increased morbidity and mortality; however, higher formalin concentrations were required to control bleeding due to radiation cystitis compared with other causes of hemorrhage.

Lowe and Stamey ${ }^{22}$ described a novel method of intravesical formalin use. This approach involves endoscopic topical placement of formalin-soaked pledgets on bleeding foci for a short period of time, and showed good results and minimal toxicity. Lojanapiwat et al. ${ }^{23}$ compared the outcomes of 11 patients treated with a single intravesical $4 \%$ formalin instillation and 8 patients treated with $10 \%$ formalin-soaked pledgets placed on the bleeding points for $15 \mathrm{~min}$; cessation of bleeding was achieved in $9(82 \%)$ of 11 patients and $6(75 \%)$ of 8 patients, respectively. These results suggest that topical application of formalin-soaked pledgets is as effective for controlling hemorrhage as conventional intravesical formalin instillation, and is associated with fewer complications.

Studies of aluminum and formalin as intravesical agents used in the treatment of severe bladder hemorrhage (independent of the cause) are compared in Table 2. In summary, aluminum should be used as the first-line intravesical instillation agent to halt severe hematuria that does not respond to continuous bladder irrigation, as it has a high response rate (78-83\%) and a more favorable toxicity profile than formalin. Intravesical formalin instillation has also been shown to be successful, with a meta-analysis reporting an overall complete response rate of $80 \%{ }^{22}$ Higher concentrations of formalin tend to produce better results, but with an increased toxicity profile. The use of placental extract and prostaglandins have been reported only in isolated cases, so cannot be recommended as part of the routine management of late hemorrhagic radiation cystitis.

\section{Systemic therapies}

Late radiation-induced changes in the bladder ultimately impair the function of the epithelium, which is then unable to maintain the integrity of the bladder-urine interface. Based on this principle, various agents have been administered systemically in order to enhance the protective polysaccharide layer (Table 3).

\section{Pentosan polysulfate}

Pentosan polysulfate is a semi-synthetic sulfated polysaccharide that serves as a synthetic glycosaminoglycan (GAG), and is thought to adhere to the bladder surface where it supplements the natural, defective GAG layer. Hampson and Woodhouse ${ }^{25}$ reported that 9 of 14 patients with hemorrhagic radiation cystitis achieved control of hematuria after treatment with oral sodium pentosan polysulfate. Sandhu et al. ${ }^{26}$ also recommended the use of oral sodium pentosan polysulfate as the primary method of managing hemorrhagic cystitis associated with pelvic radiation therapy, based on their experience with 51 patients, of whom 31 responded ( 21 had their dose reduced to a 
maintenance dose and 10 stopped treatment). The results were durable after a median follow-up of 450 days (range 19-4,526 days). No toxicities were reported, although 20 patients died from causes not related to hematuria.

\section{Conjugated estrogen}

Estrogens have been noted to have a beneficial effect in controlling hemorrhage in patients with late radiation cystitis by stabilizing vascular fragility. Liu et al. ${ }^{27}$ used conjugated estrogen in five patients unresponsive to other treatment options. Two patients received conjugated estrogen intravenously ( $1 \mathrm{mg} / \mathrm{kg}$ twice daily) for 2 days, and orally ( $5 \mathrm{mg}$ once daily) thereafter. The other three patients received only conjugated estrogen orally ( $5 \mathrm{mg}$ once daily). Four of the five patients experienced resolution of their symptoms for 12-22 months without adverse effects.

\section{WF10}

WF10 is a 1:10 dilution of tetrachlorodecaoxide formulated for intravenous delivery. Its pharmacologic actions include promotion of immune functions and tissue repair via the activation of macrophages. A multicenter, randomized, two-arm, open-label trial conducted by Veerasarn et al. $\underline{\underline{2}}$ evaluated the efficacy and safety of WF10 as an adjunct to standard treatment in the management of late radiation cystitis compared with standard treatment alone. In the WF10 group, 37 of 50 patients showed complete resolution of objective hematuria, compared with 32 of 50 patients in the standard therapy group $(P=0.28)$. Significantly fewer responders in the WF10 group experienced recurrence of hematuria compared to the standard therapy arm (17 of 37 patients versus 24 of 32 patients, $P=$ 0.01 ). A phase II study by the same authors ${ }^{29}$ evaluated 16 patients with late radiation cystitis (grade 2-3) treated with WF10. After completion of therapy, 14 patients had improvement to grade $0-1$ hematuria. At a median follow-up of 51 months, 4 of 14 patients had developed recurrent symptoms.

\section{Other interventions}

\section{Cystoscopy with fulguration}

Cystoscopy with fulguration of bleeding points is an effective method of treating hemorrhagic cystitis that is unresponsive to conservative measures. $\frac{5}{T}$ This procedure can be performed under local anesthesia, especially in females. Methods of fulguration include the use of electrocoagulation, diathermy, and argon ${ }^{30}$ or neodymium-doped yttrium-aluminum-garnet laser..${ }^{31}$ Potential morbidity following cystoscopy and fulguration includes bladder perforation with subsequent fistula formation. ${ }^{32}$ Cheng and Foo $^{33}$ reported that more-severe cases of hemorrhagic cystitis often do not respond to this treatment modality.

\section{Botulinum toxin A}

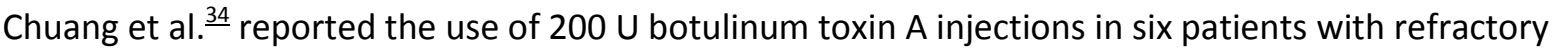
radiation cystitis. Under sedation or local anesthesia, botulinum toxin A was submucosally injected through a cystoscope into 20 sites in the trigone and floor of the bladder. A moderate to significant improvement was achieved in five of the six patients, with mean bladder capacity increasing from $105 \mathrm{ml}$ to $250 \mathrm{ml}$ and mean urinary frequency decreasing from 14 to 11 episodes per day.

\section{Orgotein}

Orgotein is an analog of the naturally occurring superoxide dismutase, and has been used in the

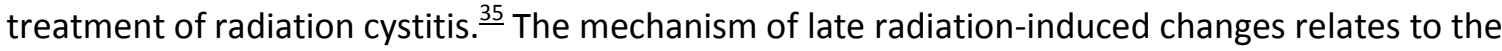
generation of free radicals, particularly the superoxide radical, which has a primary role in initiating and sustaining biologic damage and the growth of fibrotic tissue, and is responsible for the 
production of other free radicals and lipoperoxidases. Superoxide dismutase catalyzes the destruction of these superoxide radicals.

Marberger et al..$\frac{35}{}$ reported on a retrospective series of 30 patients with late radiation cystitis treated with intramural orgotein injections. Clinical improvement in symptoms and cystoscopy findings were noted in 25 of the 30 patients. Its use as an alternative option in the routine management of late radiation cystitis, however, cannot be recommended, as no further studies have been reported in the literature.

\section{Surgical interventions}

More-aggressive treatment options include selective embolization or ligation of the iliac arteries. $\underline{\underline{36}}$ Percutaneous embolization of both vesical arteries has also been described..$^{37}$ Surgical options include urinary diversion with or without cystectomy, which should be considered a last resort. Reports suggest that a transverse colon conduit is the preferred method of urinary diversion, $\frac{38}{}$ which has the advantage of using the nonirradiated bowel and ureters for creating the diversion. Alternative options for urinary diversion include percutaneous nephrostomy $\frac{39,40}{}$ and cutaneous ureterostomy. $\underline{41}^{-1}$

Complications related to the defunctionalized bladder occur in more than $50 \%$ of patients who undergo urinary diversion, ${ }^{42}$ and include pyocystis, hemorrhage, pain and neoplastic transformation; ${ }^{43}$ therefore, cystectomy is recommended at the time of urinary diversion. ${ }^{44}$ Preoperative high-dose radiation therapy contributes to increased postoperative morbidity rates, particularly enteroenteric fistulas, urointestinal fistulas and stenosis of the ureterointestinal anastomosis. ${ }^{45}$ Any alternative treatment options that are associated with less morbidity should be considered first before embarking on such debilitating surgery.

\section{Hyperbaric oxygen therapy}

Hyperbaric oxygen therapy (HBOT) involves the administration of $100 \%$ oxygen in a pressurized treatment chamber (Figure 1). The hyperbaric chamber provides conditions under which hemoglobin is fully saturated and oxygen is dissolved at very high concentrations in the blood plasma, which is then circulated to provide therapeutic benefits-such as increased angiogenesis and fibroblast activity $^{46}$-in damaged tissues. Thus, it can be considered as an alternative treatment for patients with an underlying ischemic process that is unresponsive to conventional therapy. The degree of hyperoxygenation in HBOT cannot be achieved by any other means.

HBOT has been proposed as a treatment option for patients with radiation cystitis that does not respond to conventional management, based on the rationale that it can correct ischemic injury secondary to radiation damage. A number of investigators have studied HBOT in this setting. ${ }_{47,48,49,50,}$ $51,52,53,54,55,56,57,58,59,60,61,62,63,64$ An advantage of HBOT in these patients is the absence of the adverse effects on bladder structure or function that may be seen with other therapies, such as formalin or silver nitrate instillations, while avoiding the need for surgery. HBOT is also very well tolerated, with few adverse effects - the most common being pressure-related in the form of ear and sinus barotrauma. Serious complications, such as oxygen toxicity, are very rare. ${ }^{46}$

The reported success rate of HBOT for radiation cystitis varies from $60 \%$ to $92 \%$ (Table 4). These results are highly in favor of this treatment option for refractory radiation-induced hemorrhagic cystitis. Various HBOT regimens have been used: in general, $100 \%$ oxygen is administered at pressures of 1.5-2.5 atm for 45-120 min, allowing extra time for compression and decompression. In addition, 5 min "air-breaks" can be introduced each half-hour to reduce the risk of oxygen toxicity. Sessions are administered once daily for a predetermined length of time (usually 20-30 sessions). $\frac{65}{}$ Bevers et al. $\stackrel{55}{r}$ reported the only prospective study of HBOT-a clinical trial with 40 patients seen at a 
single center over an 8-year period. All patients received HBOT for refractory radiation-induced hemorrhagic cystitis, defined as persistent or recurrent symptoms despite one or more conventional treatments. The success rate was 92\%: 30 patients had no recurrent bleeding within 3 months, 7 had a partial response with minimal bleeding, and only 3 had recurrent bleeding after a mean of 13.3 months. The severity of the initial bleeding influenced the response to HBOT. Patients with mild to moderate symptoms had a $100 \%$ response rate, and in those with severe initial bleeding the response rate was $83 \%$. Of the three patients with recurrent bleeding after successful HBOT, two had recurrent cancer, which is the most important factor associated with persistent hemorrhage after treatment.

Chong et al. $\frac{61}{r}$ reported retrospectively on the outcomes of HBOT in 60 patients over a 13-year period. The results showed an $80 \%$ overall success rate, which increased to $96 \%$ in patients treated within 6 months of the onset of hematuria, suggesting an improved outcome if HBOT is commenced early. Prior treatment with intravesical installations did not affect the outcome of HBOT. Patients who had undergone primary, adjuvant or salvage radiation therapy showed equivalent response rates $(81 \%, 83 \%$ and $78 \%$, respectively).

Del Pizzo et al..$^{57}$ reported poor long-term results, with 8 of 11 patients ultimately requiring urinary diversion to achieve definitive control of their hematuria. At a median follow-up of 2.5 years, 8 patients were asymptomatic and 3 required urinary diversion; however, at a median of 5.1 years, 5 of the 8 initially asymptomatic patients had episodes of delayed recurrent hematuria, which ultimately required urinary diversion as definitive therapy. This study highlights the progressive nature of radiation injury and the need for long-term follow-up before pronouncing that HBOT will be successful as a treatment for radiation cystitis.

The Baromedical Research Foundation in South Carolina, USA, is currently conducting the HORTIS (Hyperbaric Oxygen Radiation Tissue Injury Study) project. The principal objective of this research is to precisely determine the degree of benefit that HBOT affords in the treatment of late radiation tissue injury. The study has eight components (HORTIS-I-VIII): seven involve evaluation of established radiation tissue injury at different anatomical sites (soft tissues, mandible, bladder, rectum, colon, gynecologic and larynx); the eighth will investigate the potential of prophylactic HBOT against radiation tissue injury. ${ }^{65}$ HORTIS-III is a multicenter, prospective, double-blind, randomized, shamcontrolled trial to evaluate the effectiveness of HBOT in patients with refractory radiation cystitis; these results are eagerly awaited. ${ }^{66}$ Clarke et al. ${ }^{67}$ reported the results of HORTIS-IV, which evaluated the effectiveness of HBOT in 120 patients with refractory radiation proctitis. Patients were randomized to undergo either HBOT at $2 \mathrm{~atm}$ (group 1) or air at $1.1 \mathrm{~atm}$ (group 2). The mean LENTSOMA score improved in both groups; however, the mean score was significantly lower $(P=0.015)$, and the amount of improvement nearly twice as great ( 5.00 versus $2.61, P=0.0019)$, in group 1 compared to group 2. Group 1 also had a greater portion of responders per clinical assessment than did group $2(88.9 \%$ versus $62.5 \%, P=0.00009)$. Thus, HBOT significantly improved the healing responses in patients with refractory radiation proctitis: at 5 years' follow-up $(n=14)$, there remained a clear trend towards continued and enduring healing.

\section{Management overview}

Initial management of patients with radiation cystitis includes intravenous fluid replacement and blood transfusion if required, followed by transurethral catheterization with bladder washout and irrigation. Most patients will respond to these measures; however, if conservative management fails, intravesical instillation of alum solution should be attempted. Intravesical instillation of dilute formalin has equivalent response rates, but is associated with a higher rate of complications. Cystoscopy with electrodiathermy or laser fulguration of bleeding points is sometimes effective. Oral or parenteral agents, such as pentosan polysulfate, conjugated estrogens or WF10, should not currently be considered as part of routine management. 
Surgical options should only be considered as a last resort. These include selective embolization or ligation of internal iliac arteries, and urinary diversion (percutaneous nephrostomy, cutaneous ureterostomy or creation of bowel conduits using transverse colon or nonirradiated ileum) with cystectomy. HBOT can be used as an alternative to surgical management if available (Figure 2).

\section{Conclusions}

Radiation-induced tissue injury is categorized as either acute or late. Acute radiation injury to the bladder is usually self-limiting; however, late radiation cystitis, although relatively rare, can lead to severe hemorrhage and may be difficult to treat. Numerous treatment options have been studied over the past few decades, but many patients still ultimately require surgery to halt life-threatening hematuria. Surgery of this nature is often associated with significant morbidity, and any alternative treatment options should be explored further.

The literature reveals compelling evidence in favor of HBOT as a treatment alternative for late radiation hemorrhagic cystitis refractory to conservative measures, although the majority of studies have been retrospective case series. A sufficiently powered, multicenter, prospective, double-blind, randomized, sham-controlled trial, such as HORTIS, 6 is required to establish the true efficacy of HBOT.

\section{Review criteria}

A comprehensive PubMed search of the English-language literature published between January 1980 and September 2009 was performed for relevant articles using the Medical Subject Heading (MeSH) terms "radiation cystitis", "hemorrhagic cystitis" and "management" in various combinations. The reference lists of retrieved articles were assessed for additional articles.

\section{Key points}

- Late radiation cystitis can cause severe, life-threatening hematuria

- Oral or parenteral agents to control hematuria resulting from late radiation cystitis include conjugated estrogens, pentosan polysulfate and WF10

- Intravesical agents that can be used include alum, placental extract, prostaglandins and formalin

- Less-invasive interventions include cystoscopic fulguration of bleeding points, urinary diversion by percutaneous nephrostomy, and embolization of the internal iliac arteries

- Surgical options include urinary diversion with or without cystectomy

- Hyperbaric oxygen therapy has been reported to yield high success rates, with a low risk of complications

\section{Competing interests statement}

The authors declare no competing interests. 
Box 1 Management options for radiation cystitis

Acute radiation cystitis

Phenazopyridine

Flavoxate

Anticholinergics (e.g. oxybutynin, terodiline)

late hemorrhagic radiation cystitis

Oral and intravenous hydration, with or without blood transfusion

Bladder catheterization

Intermittent or continuous bladder irrigation

Oral or parenteral agents:

- Hematinics (e.g. tranexamic acid)

- Conjugated estrogens

- Sodium pentosan polysulfate

- WF10 (tetrachlorodecaoxide)

- Pentoxifylline

Cystoscopy, with or without:

- Fulguration (electrodiathermy or laser)

- Botulinum toxin A injection

- Orgotein injection

Intravesical instillation:

- Alum (aluminum salts)

- Silver nitrate

- Placental extract

- Prostaglandins

- Formalin

Surgery:

- Selective embolization or ligation of internal iliac arteries

- Urinary diversion: percutaneous nephrostomy, cutaneous ureterostomy or bowel conduit (transverse colon or nonirradiated ileum)

- Cystectomy and urinary diversion

Hyperbaric oxygen therapy 
Tables

Table 1 | RTOG/EORTC grading of hematuria events

\begin{tabular}{llllll}
\hline Hematuria morbidity & Grade 1 & Grade 2 & Grade 3 & Grade 4 \\
\hline $\begin{array}{l}\text { Acute hemorrhagic radiation } \\
\text { cystitis (RTOG scale) }\end{array}$ & NA & NA & $\begin{array}{l}\text { Gross hematuria with } \\
\text { or without clot passage }\end{array}$ & $\begin{array}{l}\text { Hematuria requiring } \\
\text { transfusion }\end{array}$ & $\begin{array}{l}\text { Death from } \\
\text { uncontrolled } \\
\text { hematuria }\end{array}$ \\
$\begin{array}{l}\text { Late hemorrhagic radiation } \\
\text { cystitis (RTOG/EORTC scale) }\end{array}$ & $\begin{array}{l}\text { Minor telangiectasia } \\
\text { (microscopic hematuria) }\end{array}$ & $\begin{array}{l}\text { Generalized } \\
\text { telangiectasia } \\
\text { (macroscopic hematuria) }\end{array}$ & $\begin{array}{l}\text { Severe generalized } \\
\text { telangiectasia } \\
\text { (macroscopic hematuria) }\end{array}$ & $\begin{array}{l}\text { Severe hemorrhagic } \\
\text { cystitis }\end{array}$ & $\begin{array}{l}\text { Death from } \\
\text { uncontrolled } \\
\text { hematuria }\end{array}$ \\
\hline Abbrevlations: EORTC, European Organisation for Research and Treatment of Cancer; RTOG, Radiation Therapy Oncology Group. & &
\end{tabular}

Table 2 | Studies of intravesical agents used in the treatment of severe bladder hemorrhage

\begin{tabular}{|c|c|c|c|c|}
\hline Study & Intravesical agent & Patients $(n)$ & Response rate (\%) & Adverse effects \\
\hline Arrizabalaga et al. ${ }^{11}$ & $1 \%$ aluminum & 15 & 66 & $\begin{array}{l}\text { Suprapubic pain }(n=3) \text {, vesical spasms }(n=9) \text {, } \\
\text { vesical tenesmus }(n=7)\end{array}$ \\
\hline Goswami et al. ${ }^{12}$ & $1 \%$ aluminum & 12 & 50 & Transient low-grade pyrexia $(n=4)$ \\
\hline Castillo and Buizza ${ }^{14}$ & $1 \%$ aluminum & 7 & 100 & None reported \\
\hline Takashi et al..68 & $1 \%$ aluminum & 9 & 78 & None reported \\
\hline Ferrie et al. ${ }^{19}$ & $10 \%$ formalin & 14 & 93 & Reduced bladder capacity $(n=5)$ \\
\hline Vicente et al..$^{20}$ & $\begin{array}{l}4 \% \text { formalin } \\
10 \% \text { formalin }\end{array}$ & $\begin{array}{l}19 \\
6\end{array}$ & 88 & $\begin{array}{l}\text { Rectovesical fistula }(n=1) \\
\text { hydroureteronephrosis }(n=1) \\
\text { extravasation of formalin }(n=1)\end{array}$ \\
\hline Dewan et al.21 & $\begin{array}{l}1 \% \text { formalin } \\
2 \% \text { formalin } \\
4 \% \text { formalin }\end{array}$ & $\begin{array}{l}22 \\
10 \\
4\end{array}$ & 89 & $\begin{array}{l}\text { Minor complications }(n=19), \text { major } \\
\text { complications }(n=11) \text {, mortality }(n=1)\end{array}$ \\
\hline Lojanapiwat et al. ${ }^{23}$ & $\begin{array}{l}4 \% \text { formalin } \\
10 \% \text { formalin- } \\
\text { soaked pledgets }\end{array}$ & $\begin{array}{l}11 \\
8\end{array}$ & $\begin{array}{l}82 \\
75\end{array}$ & Fewer complications associated with pledgets \\
\hline Donahue and Frank $\mathrm{k}^{24}$ & $\begin{array}{l}10 \% \text { formalin } \\
5 \% \text { formalin } \\
1 \% \text { formalin }\end{array}$ & $\begin{array}{l}123 \\
91 \\
21\end{array}$ & $\begin{array}{l}83 \\
78 \\
71\end{array}$ & $\begin{array}{l}\text { Higher morbidity and mortality associated with } \\
5 \% \text { and } 10 \% \text { formalin compared to } 1 \% \text { formalin }\end{array}$ \\
\hline
\end{tabular}

Table 3 | Studies of systemic therapies used in the treatment of late radiation cystitis

\begin{tabular}{llllll}
\hline Study & Systemic therapy & Patients $(n)$ & Response rate (\%) & Follow-up duration (months) & Adverse effects \\
\hline $\begin{array}{l}\text { Hampson and } \\
\text { Woodhouse }{ }^{25}\end{array}$ & $\begin{array}{l}\text { Pentosan } \\
\text { polysulfate }\end{array}$ & 13 & 69 & NR & None \\
\hline Sandhu et al. & $\begin{array}{l}\text { Pentosan } \\
\text { polysulfate }\end{array}$ & 52 & 58 & 14.5 & None \\
\hline Liu et al. ${ }^{27}$ & $\begin{array}{l}\text { Conjugated } \\
\text { estrogens }\end{array}$ & 5 & 80 & 15 & None \\
\hline Veerasarn et al. ${ }^{28}$ & WF10 & 50 & 74 & 12 & None \\
\hline Veerasarn et al. ${ }^{29}$ & WF10 & 16 & 88 & 51 & None \\
\hline
\end{tabular}

Abbreviation: NR, not reported.

Table 4 | Studies of hyperbaric oxygen therapy in patients with radiation cystitis

\begin{tabular}{llllll}
\hline Study & Patients $(\boldsymbol{n})$ & $\begin{array}{l}\text { Treatment sessions } \\
\text { per patient }(\boldsymbol{n})\end{array}$ & $\begin{array}{l}\text { Length of each } \\
\text { treatment session }(\mathbf{m i n})\end{array}$ & Response rate (\%) & $\begin{array}{l}\text { Follow-up } \\
\text { duration (months) }\end{array}$ \\
\hline Rijkmans et al..$^{50}$ & 10 & 20 & 90 & 60 & $2-24 *$ \\
\hline Weiss et al. ${ }^{54}$ & 13 & 60 & 120 & 92 & $30(4-102)^{\ddagger}$ \\
\hline Bevers et al. ${ }^{55}$ & 40 & 20 & 90 & 92 & $13(1-74)^{5}$ \\
\hline Del Pizzo et al. ${ }^{57}$ & 11 & 40 & 90 & 73 & $61(38-102)^{5}$ \\
\hline Mathews et al. ${ }^{58}$ & 17 & 14 & 90 & 89 & $21(9-60)^{\ddagger}$ \\
\hline Corman et al. ${ }^{\infty 0}$ & 57 & 33 & 90 & 86 & $10-120^{*}$ \\
\hline Chong et al. ${ }^{51}$ & 60 & 33 & 90 & 80 & 12 l \\
\hline
\end{tabular}

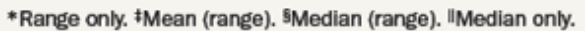




\section{Figures}
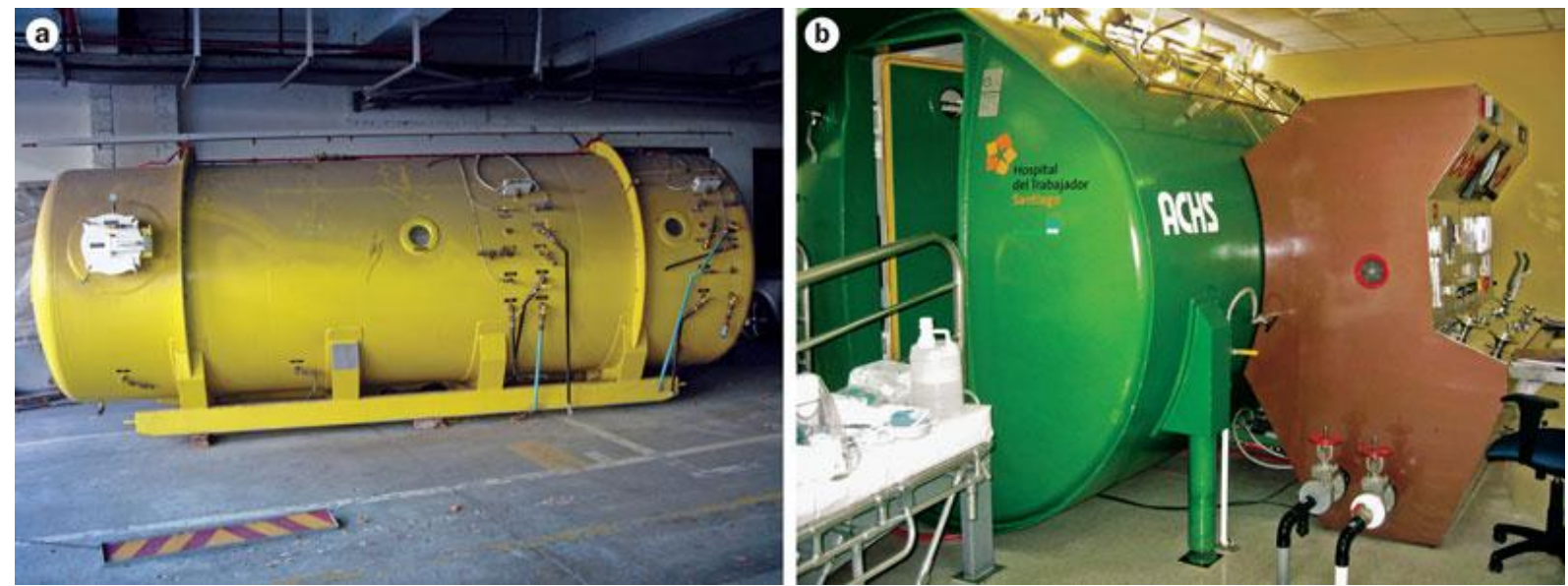

Figure 1 Hyperbaric oxygen chambers

a | Newly delivered hyperbaric chamber prior to installation. b | Hyperbaric oxygen chamber with control panel.

\begin{tabular}{|c|}
\hline $\begin{array}{l}\text { Diagnosis } \\
\text { Exclude urinary tract infection and recurrence of malignancy } \\
\text { Investigations: urine culture; cystoscopy with or without biopsy; } \\
\text { intravenous urography or ultrasonography of the urinary tract }\end{array}$ \\
\hline$\downarrow$ \\
\hline $\begin{array}{l}\text { Conservative measures } \\
\text { Oral and intravenous hydration } \\
\text { Blood transfusion } \\
\text { Bladder catheterization } \\
\text { Intermittent or continuous bladder irrigation }\end{array}$ \\
\hline$\downarrow$ \\
\hline $\begin{array}{l}\text { Intravesical instillation } \\
\text { Alum } \\
\text { Formalin }\end{array}$ \\
\hline$\downarrow$ \\
\hline Cystoscopy (with or without fulguration) \\
\hline$\downarrow$ \\
\hline Hyperbaric oxygen therapy \\
\hline$\downarrow$ \\
\hline $\begin{array}{l}\text { Surgical intervention } \\
\text { Selective embolization or ligation of internal iliac arteries } \\
\text { Urinary diversion } \\
\quad \text { Percutaneous nephrostomies } \\
\text { Cutaneous ureterostomies } \\
\text { Bowel conduit (transverse colon or nonirradiated ileum) } \\
\text { Cystectomy and urinary diversion }\end{array}$ \\
\hline
\end{tabular}

Figure 2 Algorithm illustrating the recommended management of late hemorrhagic radiation cystitis 


\section{References}

1. Rubin, E. \& Farber, J. L. in Essential Pathology: Second Edition (Rubin, E. \& Farber, J. L.) 194195 (J. B. Lippincott Company, Philadelphia, 1995).

2. Russell, N. S. \& Bartelink, H. Radiotherapy: the last 25 years. Cancer Treat. Rev. 25, 365-376 (1999).

3. Marks, L. B., Carroll, P. R., Dugan, T. C. \& Anscher, M. A. The response of the urinary bladder, urethra and ureter to radiation and chemotherapy. Int. J. Radiat. Oncol. Biol. Phys. 31, 12571280 (1995).

4. Denton, A. S., Clarke, N. W. \& Maher, E. J. Non-surgical interventions for late radiation cystitis in patients who have received radical radiotherapy to the pelvis. Cochrane Database of Systematic Reviews, Issue 3, Art. No.: CD001773. doi: 10.1002/14651858.CD001773 (2002).

5. Levenback, C., Eifel, P. J., Burke, T. W., Morris, M. \& Gershenson, D. M. Hemorrhagic cystitis following radiotherapy for stage Ib cancer of the cervix. Gynecol. Oncol. 55, 206-210 (1994).

6. Goodman, G. P., Hislop, T. G., Elwood, J. M. \& Balfour, J. Conservation of bladder function in patients with bladder function in patients with invasive bladder cancer treated by definitive irradiation and selective cystectomy. Int. J. Radiat. Oncol. Biol. Phys. 7, 569-573 (1981).

7. Pavy, J.-J. et al. Late effects toxicity scoring: the SOMA scale. Int. J. Radiat. Oncol. Biol. Phys. 31, 1043-1047 (1995).

8. Power, D. A. Late effects of radiotherapy: how to assess and improve outcomes. Br. J. Radiol. 78, 150-152 (2005).

9. De Vries, C. R. \& Freiha, F. S. Hemorrhagic cystitis: a review. J. Urol. 143, 1-9 (1990).

10. National Cancer Institute. Cancer Therapy Evaluation Program: Protocol Development [online], (2009).

11. Arrizabalaga, M. et al. Treatment of massive haematuria with aluminous salts. Br. J. Urol. 60, 223-226 (1987).

12. Goswami, A. K., Mahajan, R. K., Nath, R. \& Sharma, S. K. How safe is $1 \%$ alum irrigation in controlling intractable vesical hemorrhage? J. Urol. 149, 264-267 (1993).

13. Phelps, K. R., Naylor, K., Brien, T. P., Wilbur, H. \& Haqqie, S. S. Encephalopathy after bladder irrigation with alum: case report and literature review. Am. J. Med. Sci. 318, 181-185 (1999).

14. Octavio Castillo, A. \& Buizza, C. Bladder irrigation with aluminum solution for the control of massive haematuria [Italian]. Arch. Ital. Urol. Nefrol. Androl. 61, 59-62 (1989).

15. Micic, S. \& Genbacev, O. Post-irradiation cystitis improved by instillation of early placental extract in saline. Eur. Urol. 14, 291-293 (1988).

16. Miura, M. et al. Effective hyperbaric oxygenation with prostaglandin E1 for radiation cystitis and colitis after pelvic radiotherapy. Int. Urol. Nephrol. 28, 643-647 (1996).

17. Hemal, A. K., Vaidyanathan, S., Sankaranarayanan, A., Ayyagari, S. \& Sharma, P. L. Control of massive vesical hemorrhage due to radiation cystitis with intravesical instillation of 15 (s) 15methyl prostaglandin F2-alpha. Int. J. Clin. Pharmacol. Ther. Toxicol. 26, 477-478 (1988).

18. Hemal, A. K., Praveen, B. V., Sankaranarayanan, A. \& Vaidyanathan, S. Control of persistent vesical hemorrhage due to radiation cystitis by intravesical instillation of 15 (s) 15-methyl prostaglandin F2-alpha. Indian J. Cancer 26, 99-101 (1989).

19. Ferrie, B. G., Rundle, J. S., Kirk, D., Paterson, P. J. \& Scott, R. Intravesical formalin in intractable haematuria. J. Urol. (Paris) 91, 33-35 (1985).

20. Vicente, J., Rios, G. \& Caffaratti, J. Intravesical formalin for the treatment of massive hemorrhagic cystitis: retrospective review of 25 cases. Eur. Urol. 18, 204-206 (1990).

21. Dewan, A. K., Mohan, G. M. \& Ravi, R. Intravesical formalin for hemorrhagic cystitis following irradiation for cancer of the cervix. Int. J. Gynaecol. Obstet. 42, 131-135 (1993).

22. Lowe, B. A. \& Stamey, T. A. Endoscopic topical placement of formalin soaked pledgets to control localized hemorrhage due to radiation cystitis. J. Urol. 158, 528-529 (1997).

23. Lojanapiwat, B., Sripralakrit, S., Soonthornphan, S. \& Wudhikarn, S. Intravesicle formalin instillation with a modified technique for controlling haemorrhage secondary to radiation cystitis. Asian J. Surg. 25, 232-235 (2002). 
24. Donahue, L. A. \& Frank, I. N. Intravesical formalin for hemorrhagic cystitis: analysis of therapy. J. Urol. 141, 809-812 (1989).

25. Hampson, S. J. \& Woodhouse, C. R. Sodium pentosanpolysulphate in the management of haemorrhagic cystitis: experience with 14 patients. Eur. Urol. 25, 40-42 (1994).

26. Sandhu, S. S., Goldstraw, M. \& Woodhouse, C. R. The management of haemorrhagic cystitis with sodium pentosan polysulphate. BJU Int. 94, 845-847 (2004).

27. Liu, Y. K. et al. Treatment of radiation or cyclophosphamide induced hemorrhagic cystitis using conjugated estrogen. J. Urol. 144, 41-43 (1990).

28. Veerasarn, V. et al. Reduced recurrence of late haemorrhagic radiation cystitis by WF10 therapy in cervical cancer patients. A multicentre, randomized, two-arm, open-label trial. Radiother. Oncol. 73, 179-185 (2004).

29. Veerasarn, V., Boonnuch, W. \& Kakanaporn, C. A phase II study to evaluate WF10 in patients with late radiation hemorrhagic cystitis and proctitis. Gynaecol. Oncol. 100, 179-184 (2006).

30. Wines, M. P. \& Lynch, W. D. A new minimally invasive technique for treating radiation cystitis: the argon-beam coagulator. BJU Int. 98, 610-612 (2006).

31. Ravi, R. Endoscopic neodymium:YAG laser treatment of radiation-induced hemorrhagic cystitis. Lasers Surg. Med. 14, 83-87 (1994).

32. Vicente Rodriguez, J. \& Farina, L. A. Intestinal perforation after treatment of radiation cystitis using the neodymium:YAG laser [Spanish]. Actas Urol. Esp. 15, 459-461 (1991).

33. Cheng, C. \& Foo, K. T. Management of severe chronic radiation cystitis. Ann. Acad. Med. Singapore 21, 368-371 (1992).

34. Chuang, Y. C., Kim, D. K., Chiang, P. H. \& Chancellor, M. B. Bladder botulinum toxin A injection can benefit patients with radiation and chemical cystitis. BJU Int. 102, 704-706 (2008).

35. Marberger, H., Hubert, W., Menander-Huber, K. B. \& Bartsch, G. Orgotein: a new drug for the treatment of radiation cystitis. Eur. J. Rheumatol. Inflamm. 4, 244-249 (1981).

36. Rodríguez-Patrón Rodríguez, R. et al. Hypogastric artery embolization as a palliative treatment for bleeding secondary to intractable bladder or prostate disease [Spanish]. Arch. Esp. Urol. 56, 111-118 (2003).

37. De Berardinis, E. et al. Superselective embolization of bladder arteries in the treatment of intractable bladder haemorrhage. Int. J. Urol. 12, 503-505 (2005).

38. Ravi, R., Dewan, A. K. \& Pandey, K. K. Transverse colon conduit urinary diversion in patients treated with very high dose pelvic irradiation. Br. J. Urol. 73, 51-54 (1994).

39. Zagoria, R. J., Hodge, R. G., Dyer, R. B. \& Routh, W. D. Percutaneous nephrostomy for treatment of intractable hemorrhagic cystitis. J. Urol. 149, 1449-1451 (1993).

40. Sneiders, A. \& Pryor, J. L. Percutaneous nephrostomy drainage in the treatment of severe hemorrhagic cystitis. J. Urol. 150, 966-967 (1993).

41. Pomer, S., Karcher, G. \& Simon, W. Cutaneous ureterostomy as last resort treatment of intractable haemorrhagic cystitis following radiation. Br. J. Urol. 55, 392-394 (1983).

42. Fazili, T., Bhat, T. R., Masood, S., Palmer, J. H. \& Mufti, G. R. Fate of the leftover bladder after supravesical urinary diversion for benign disease. J. Urol. 176, 620-621 (2006).

43. Adeyoju, A. B., Lynch, T. H. \& Thornhill, J. A. The defunctionalized bladder. Int. Urogynecol. J. Pelvic Floor Dysfunct. 9, 48-51 (1998).

44. Adeyoju, A. B. et al. The fate of the defunctioned bladder following supravesical urinary diversion. Br. J. Urol. 78, 80-83 (1996).

45. Bondavalli, C. et al. Complications of urinary diversion after radiotherapy [Italian]. Arch. Ital. Urol. Androl. 75, 10-13 (2003).

46. Capelli-Schellpfeffer, M. \& Gerber, G. S. The use of hyperbaric oxygen in urology. J. Urol. 162, 647-654 (1999).

47. Weiss, J. P. et al. Treatment of radiation-induced cystitis with hyperbaric oxygen. J. Urol. 134, 352-354 (1985).

48. Schoenrock, G. J. \& Cianci, P. Treatment of radiation cystitis with hyperbaric oxygen. Urology 27, 271-272 (1986). 
49. Weiss, J. P. \& Neville, E. C. Hyperbaric oxygen: primary treatment of radiation-induced hemorrhagic cystitis. J. Urol. 142, 43-45 (1989).

50. Rijkmans, B. G., Bakker, D. J., Dabhoiwala, N. F. \& Kurth, K. H. Successful treatment of radiation cystitis with hyperbaric oxygen. Eur. Urol. 16, 354-356 (1989).

51. Nakada, T. et al. Successful hyperbaric oxygenation for radiation cystitis due to excessive irradiation to uterus cancer. Eur. Urol. 22, 294-297 (1992).

52. Norkool, D. M., Hampson, N. B., Gibbons, R. P. \& Weissman, R. M. Hyperbaric oxygen therapy for radiation-induced hemorrhagic cystitis. J. Urol. 150, 332-334 (1993).

53. Lee, H. C., Liu, C. S., Chiao, C. \& Lin, S. N. Hyperbaric oxygen therapy in hemorrhagic radiation cystitis: a report of 20 cases. Undersea Hyperb. Med. 21, 321-327 (1994).

54. Weiss, J. P., Mattei, D. M., Neville, E. C. \& Hanno, P. M. Primary treatment of radiationinduced hemorrhagic cystitis with hyperbaric oxygen: 10 year experience. J. Urol. 151, 15141517 (1994).

55. Bevers, R. F. M., Bakker, D. J. \& Kurth, K. H. Hyperbaric oxygen for treatment of haemorrhagic radiation cystitis. Lancet 346, 803-805 (1995).

56. Peusch-Dreyer, D., Dreyer, K. H., Müller, C. D. \& Carl, U. Management of postoperative radiation injury of the urinary bladder by hyperbaric oxygen (HBO). Strahlenther. Onkol. 174 (Suppl. 3), 99-100 (1998).

57. Del Pizzo, J. J. D., Chew, B. H., Jacobs, S. C. \& Sklar, G. N. Treatment of radiation induced hemorrhagic cystitis with hyperbaric oxygen: long-term followup. J. Urol. 160, 731-733 (1998).

58. Mathews, R., Rajan, N., Josefson, L., Camporesi, E. \& Makhuli, Z. Hyperbaric oxygen therapy for radiation induced hemorrhagic cystitis. J. Urol. 161, 435-437 (1999).

59. Mayer, R. et al. Hyperbaric oxygen - an effective tool to treat radiation morbidity in prostate cancer. Radiother. Oncol. 61, 151-156 (2001).

60. Corman, J. M., McClure, D., Pritchett, R., Kozlowski, P. \& Hampson, N. Treatment of radiation induced hemorrhagic cystitis with hyperbaric oxygen. J. Urol. 169, 2200-2202 (2003).

61. Chong, K. T., Hampson, N. \& Corman, J. M. Early hyperbaric oxygen therapy improves outcome for radiation-induced hemorrhagic cystitis. Urology 65, 649-653 (2005).

62. Neheman, A., Nativ, O., Moskovitz, B., Melamed, Y. \& Stein, A. Hyperbaric oxygen therapy for radiation-induced haemorrhagic cystitis. BJU Int. 96, 107-109 (2005).

63. Yoshida, T. et al. Hyperbaric oxygen therapy for radiation-induced hemorrhagic cystitis. Int. J. Urol. 15, 639-641 (2008).

64. Safra, T. et al. Improved quality of life with hyperbaric oxygen therapy in patients with persistent pelvic radiation-induced toxicity. Clin. Oncol. (R. Coll. Radiol.) 20, 284-287 (2008).

65. The Baromedical Research Foundation. Project HORTIS overview [online], (2010).

66. Clinicaltrials.gov. Study to determine if hyperbaric oxygen therapy is helpful for treating radiation tissue injuries [online].

67. Clarke, R. E. et al. Hyperbaric oxygen treatment of chronic refractory radiation proctitis: a randomized and controlled double-blind crossover trial with long-term follow-up. Int. J. Radiat. Oncol. Biol. Phys. 72, 134-143 (2008).

68. Takashi, M., Kondo, A., Kato, K., Murase, M. \& Miyake, K. Evaluation of intravesical alum irrigation for massive bladder hemorrhage. Urol. Int. 43, 286-288 (1988). 